\title{
Design and Implementation of an Open-Source Computer-Based Testing System with End User Impact Analysis in Africa
}

\author{
Oyetoke Oluwole \\ Department of Electrical and Information Engineering, Covenant University, Ota, Ogun, Nigeria \\ Email: oluwoleoyetoke@gmail.com, oluwole.oyetoke@covenantuniversity.edu.ng
}

\begin{abstract}
The System is a Java Desktop Application designed by the integration of Java and MySQL to help provide a platform whereby computer-based tests can be organized and performed. The basic idea behind designing the system to have a fluid outlook and functional over a Wi-Fi network is simply to offer an operational scheme that is easy to implement by high schools, tertiary institutions and examination bodies with the intention of downloading and adapting it for their own use. Also, to provide a platform whereby prospective CBT examinees can have continuous practice and prior acquaintance with the nitty-gritty of computer based testing in general. This paper concludes by surveying and analyzing the impact of this initiative (being freely available for use and adaptation) on prospective CBT candidate's test performance.
\end{abstract}

Index Terms - Computer-Based Test, Education, Java, MySQL, Database, UTME, JAMB, Wi-Fi.

\section{INTRODUCTION}

The world has now become the then forecasted global village with the advent of the internet and various wireless communication technologies. Also, the world of computers has seen massive improvements both in speed and power coupled with the reduction in their cost. This has since brought in a new trend in the mode of test delivery across all educational fields and levels. Testing bodies and organizations can now conveniently deploy their tests to even the remotest parts of the world, on a steady basis. Coming along with this growth in technology is the improvement in the economic and technological capability of many African countries, making Africa a partisan adopter of this new method of test delivery. It is quite notable that despite the widespread embrace of this initiative, it can be said that what has been left unaddressed is the slippery slope peculiar to the African context, one of which is notably the exposure level of most candidates to similar systems prior to taking the main test. This paper shows the complete design and implementation of a Computer-Based Testing System which addresses some of these issues. It also tests and makes analysis of the impact this solution has on prospective exam takers.
The System is divided into two parts, the JAMB/UTME CBT and the SCHOOL CBT.

\section{A. Jamb/Utme Cbt}

UTME in Nigeria stands for the Unified Tertiary Matriculation Examination formerly administered by the Joint Admissions and Matriculations Board (JAMB) in Nigeria. It is an examining body which organizes tertiary matriculation examinations for prospective undergraduates. In recent years, the examining body decided to cede the paper based test for online computer based tests. Upon introduction of this new platform, many examinees faced the daunting task of utilizing the system, considering the fact that a good number of the candidates had no prior experience with CBTs and were not computer literate. This explains the motive behind the first part of the CBT System which was solely designed to be a replica of the Original UTME CBT system in use and dedicated to helping prospective examinees have first-hand practice. The System is launched with three (3) already pre-installed examination packs, each scheduled for $3 \mathrm{hrs}: 45$ minutes.

\section{B. School Cbt}

The SCHOOL CBT is designed for institutions with the desire to constantly set up computer-based tests for their students. This section of the system offers the flexibility of setting the examination parameters (time, number of questions etc), upload of questions and indicating which student(s) or class(es) can take part in the exam. Special features such as withholding and releasing student's results are also included.

\section{RELEVANCE AND APPLICATION OF THE CBT SYSTEM}

\section{A. Serves as a Preparatory Tool}

To provide intending CBT examinees in any part of the world with a robust platform for practicing and preparing, thereby improving their performances (inference derived from the impact analysis)

\section{B. Cost Cut}

The application software is designed to be implementable and adaptable by high schools and other tertiary institutions for free, thereby cutting the cost of 
implementation for such bodies which might need to put their students through a training process ahead of the main external examination.

\section{UTME Practice}

A section of the software is designed for the Nigerian Unified Tertiary Matriculations Examination (UTME) previously known as Joint Admissions and Matriculations Board Examination (JAMB). With this, users can prepare for the UTME examination in Nigeria, at no cost.

\section{COMPUTER-BASED TEST FundAMENTALS}

Computer-Based Test (CBT) as the name implies refers to a kind of test whose primary means of delivery is via the use of a computer. This test is mostly carried out using a software product installed on the computer or online via a web browser. Computer-based testing has emerged as one of the recent "innovative" approaches to assessments most pursued by institutions and examining bodies. It is lauded to be the answer to having a cheaper and speedier test delivery for exams with massive candidates [1].

\section{A. Contextual Issues Related To Computer-Based Testing}

The implementation of CBT occurs within a context that both supports and limits its use [1]. Below are some of the contextual issues facing the Computer Based Testing platform in Africa:

1) Down Side

a) Technological Capacity of Schools: This is noticeable in most African schools

b) Access to Testing Centres, Practice or Demo Software: Some testing institutions only make available the demo to the upcoming exam in the initializing moments of the actual test [2].

c) Security of CBT: The security measures incoporated for computer based tests deployed over the internet most at times are circumvented, thereby compromising the integrity of the test

d) Reliability of Test Delivery System: Due to hardware peculiarities.

e) Access to a Computers: Nigeria, Africa's most populous nation, has a personal computer penetration rate of just 4.5 percent (According to the National Bureau of Statistics) [3]. USA being the country with the highest penetration has $61.8 \%$ of households having access to a computer (March 2013) [4] and a global rating of $17 \%$ per capita, it can be concluded that a good sample of test takers per time might not have had prior access or frequent usage of a computer talk less of practicing times.

2) Good Side

a) Time Saving: Test can be offered at any given time provided the required hardware is available. This leads to sustainable reduction in the time between test administration and scoring [2].

b) Automation: Automates the examination delivery, assesment and recording process, therby minimizing clerical mistakes

c) Eco-Friendliness: Slashed the use of paper, thereby making it an eco friendly initiative

d) Impoved Statistical Analysis: More improved analysis of students performance can be done at no extra cost and faster

\section{METHODOLOGY}

\section{A. Major Design Consideration}

1) Consistency and simplicity to the end user

2) GUI attractiveness and theme appeal

\section{B. Programming Process}

1) Specifying the problem

2) Analysing the problem

3) Designing an algorithm

4) Coding the algorithm into Java

5) Test the program

\section{Design Approach}

With the application pulling and storing resources from and in the database via the use of the Java Database Connector (JDBC), the end user (Admin \& Student) is able to perform various operations e.g. CBTs and have the required data stored in an organized manner for futuristic retrieval. The software can be used simultaneously across various computers over a Wi-Fi enabled network

To fully put in use, user will have to pre install a server (e.g. Wamp Server) on the computer which will serve the application to other computers on the Wi-Fi enabled network. Thereafter, the user will need to start the server and import the Software's Database as provided. For this software to run, the user has to always have the server running.

- IDE Used - Java Netbeans 8.0

- Source/Binary Format - JDK 7

The block diagram below shows how the major units of the software functioning collaboratively

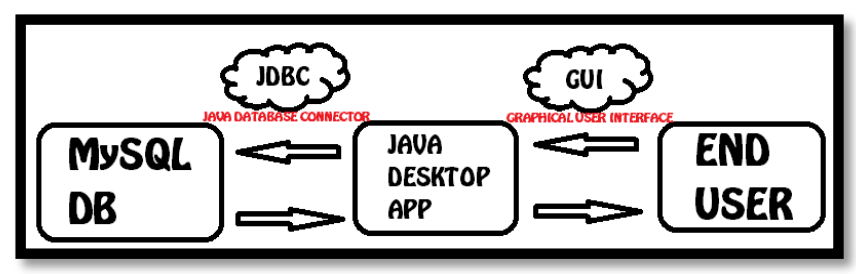

Fig.1. Block Diagram Illustrating Software Component Interaction 


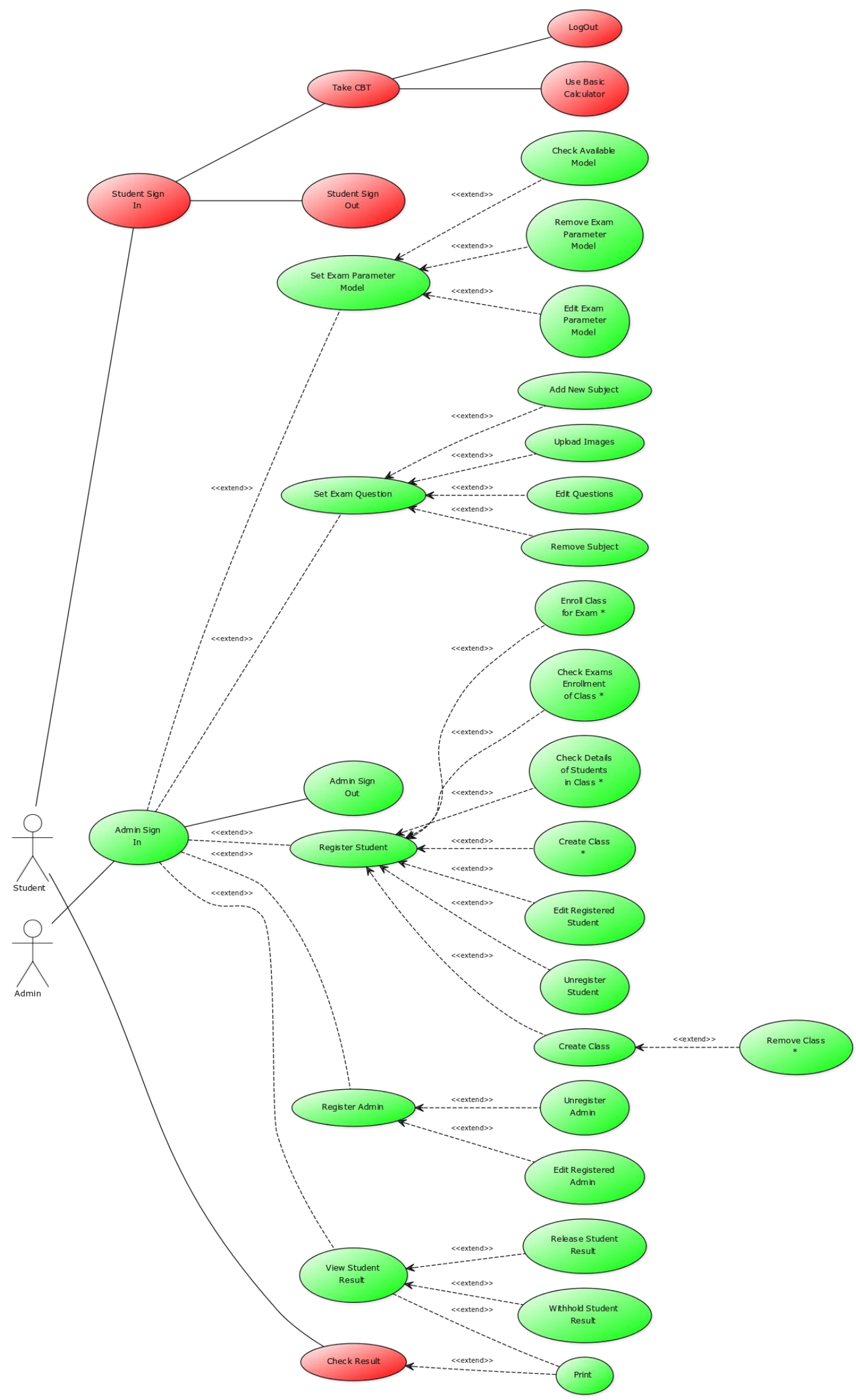

Fig.2. Use Case Diagram for the CBT System 


\section{Software Component Breakdown}

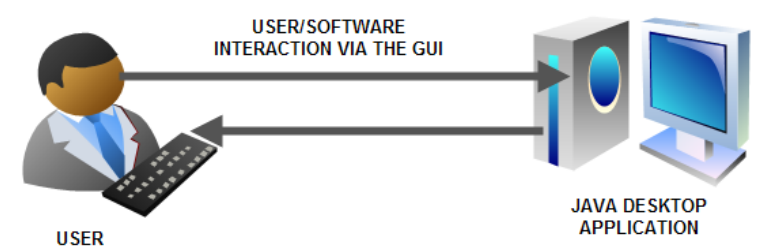

Fig.3. User-Software Interaction

\section{1) USER INTERFACE}

The User Interface of any software is responsible for all interactions of the software with the user. A graphical User Interface (GUI) takes advantage of the computer's graphics capabilities to make the program easier to use. A well-designed graphical user interfaces can free the user from learning complex command languages [5]. It can also be termed a visual way of interacting with a computer [6]. A good GUI is usually characterized by
a) Ease of learning
b) Consistency
c) Speed of use
d) Difficulty in committing errors
e) Aesthetics
f) Efficient feedback system
g) Ability to provide adequate guidance

The User interface portion of this software was designed using the drag and drop functionality of Netbeans IDE 8.0

\section{2) DATABASE}

A database is a separate application that stores a collection of data [7].

\section{3) $J D B C$}

Java programs communicate with databases and manipulate their data using the Java Database Connectivity (JDBC) API. A JDBC driver enables Java applications to connect to a database in a particular Data Base Management System and allows you to manipulate that database using the JDBC API [8].

\section{4) $R D B M S$}

Nowadays, we use relational database management systems (RDBMS) to store and manage huge volume of data. This is called relational database because all the data is stored into different tables and relations are established using primary keys or other keys known as foreign keys [7].

\section{5) $M y S Q L$}

MySQL is a fast, easy-to-use RDBMS released under an open source license being used for many small and big businesses [8]. MySQL pronounced 'My sequel' has the following known advantages:

a) MySQL is released under an open-source license.
So you have nothing to pay to use it.

b) MySQL uses a standard form of the well-known SQL data language.

c) MySQL works on many operating systems and with many languages including PHP, PERL, C, $\mathrm{C}++$, JAVA, etc.

d) MySQL works very quickly and works well even with large data sets.

e) MySQL supports large databases, up to 50 million rows or more in a table. The default file size limit for a table is $4 \mathrm{~GB}$, but you can increase this (if your operating system can handle it) to a theoretical limit of 8 million terabytes (TB).

\section{E. Software Component Interaction}

Fig. 4 shows the five (5) basic actions carried out by the Java Desktop CBT Application via the use of the JDBC API in collaboration with the JDBC driver.

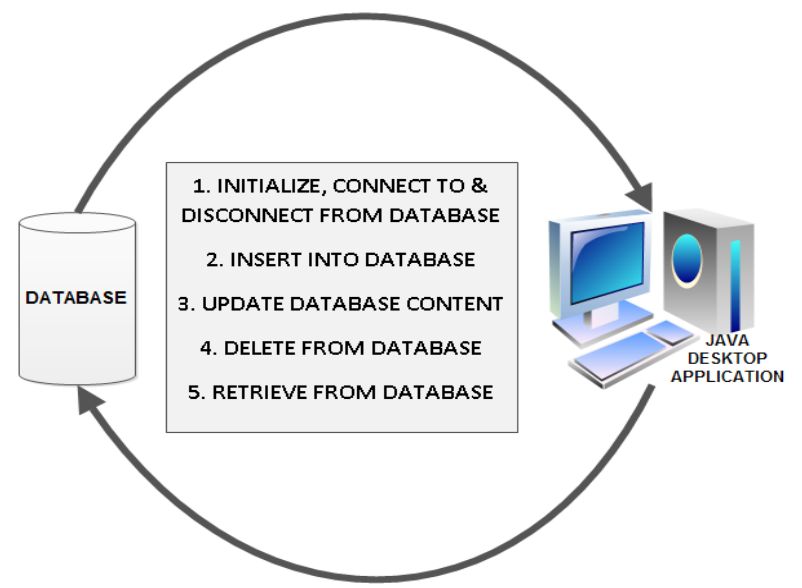

Fig.4. Diagram Showing the Basic Transactions Happening Between the Desktop Application and the Database

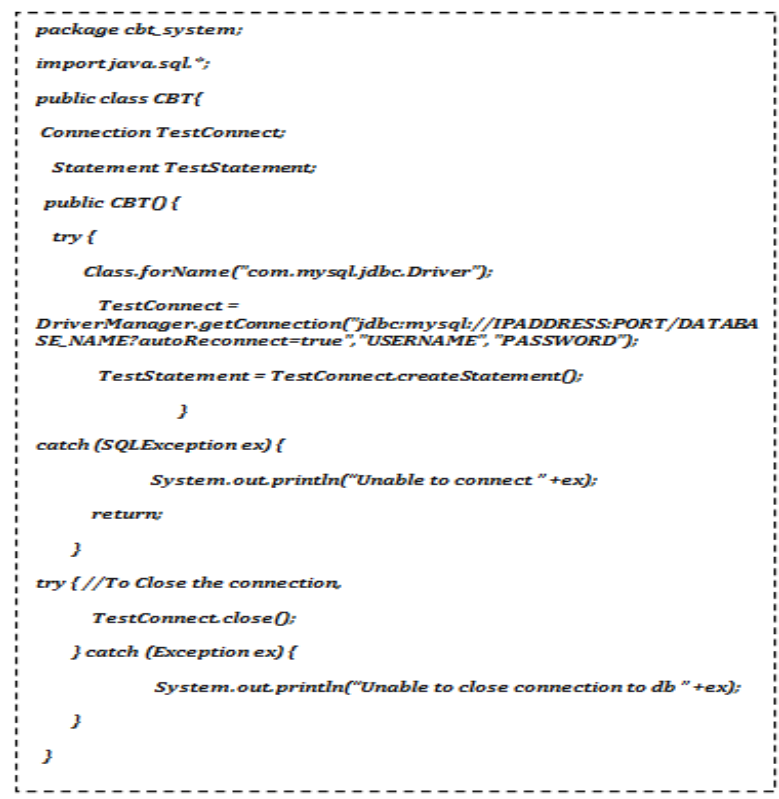

Fig.5. Code Excerpt Showing How to Initialize, Connect To and Disconnect From the Database 


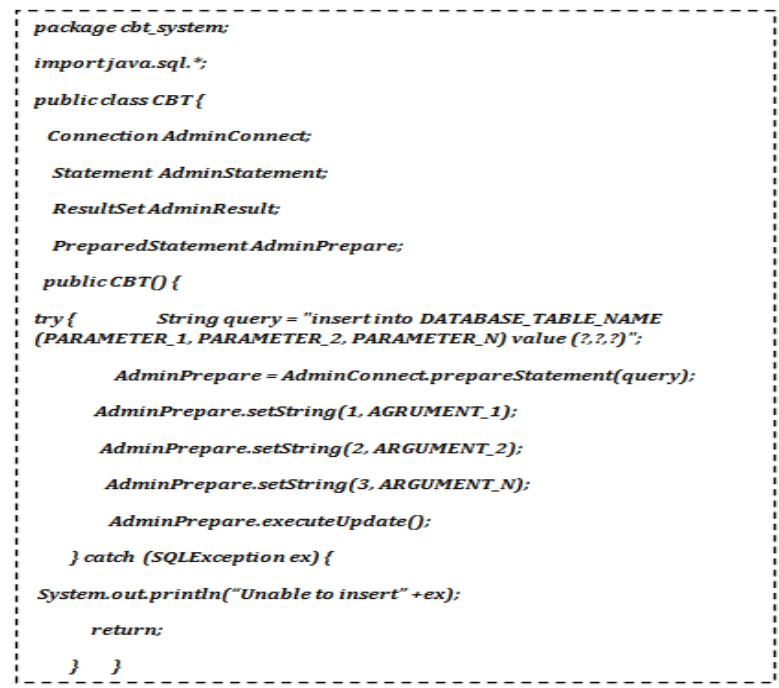

Fig.6. Code Excerpt Showing How to Insert Data into the Database

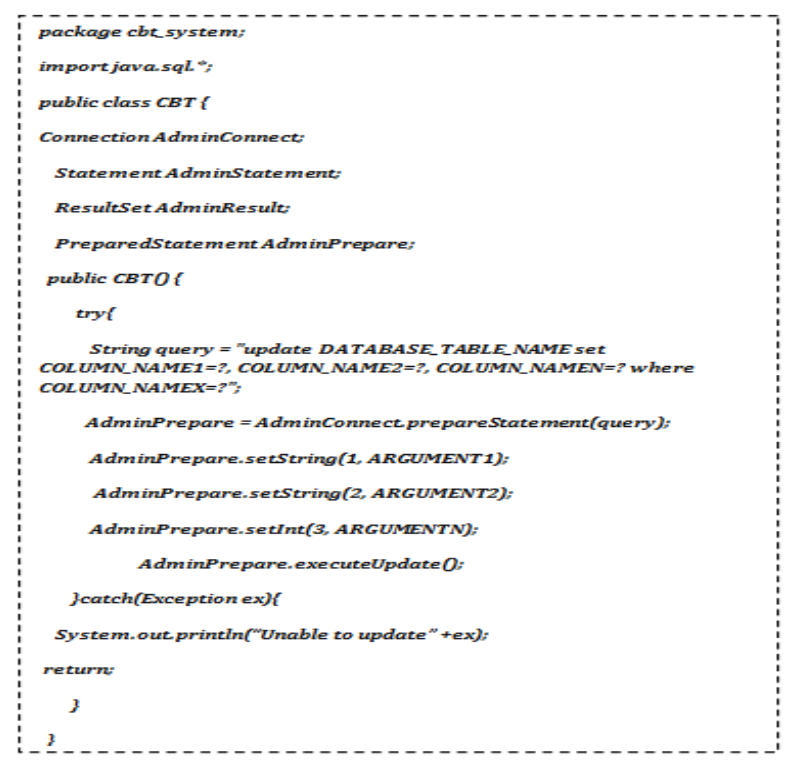

Fig.7. Code Excerpt Showing How to Update the Data in the Database

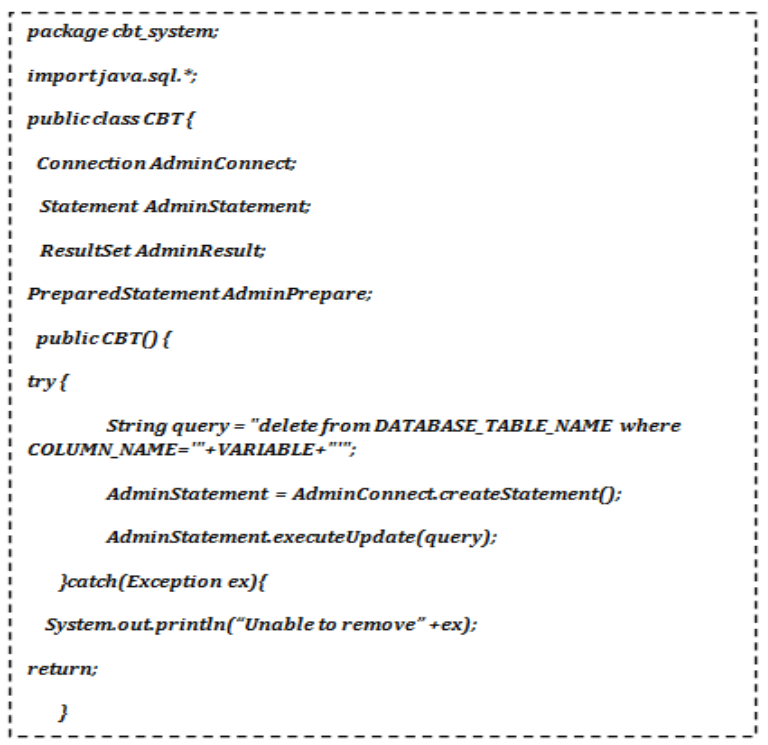

Fig.8. Code Excerpt Showing How to Delete Data from the Database

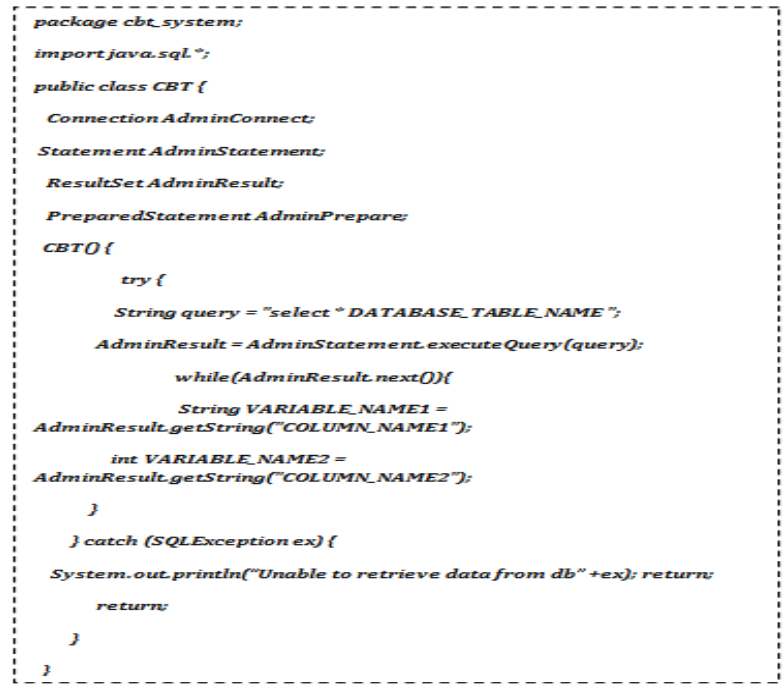

Fig.9. Code Excerpt Showing How to Retrieve Data from Database

The software development methodology used is the itiritative and incremental development methodology. Iterative and Incremental development is any combination of both iterative design and incremental build model for software development [9]. During software development, more than one iteration of the software development cycle may be in progress at the same time and this process may be described as an 'evolutionary acquisition' or 'incremental build' approach [10]. Below are the excerpts of the required codes needed in Java to carry out the actions shown in the diagram above.

\section{IMPLEMENTATION}

The CBT System is built to be able to perform over fifty (50) different operations ranging from taking tests, administering test, checking results and many other functionalities (download manual for more details). Fig. 10 shows the software's home screen, from which the user can decide to use either the JAMB/UTME CBT or SCHOOL CBT System depending on which suites his/her needs.

Examinees have the flexibility of choosing from the available examination questions. The software is kitted by default with 3 complete practice questions for previous years of the Nigerian UTME examination. For the SCHOOL CBT system, candidates will be asked to input password as instructed by Admin

The software is designed to write vital examination variable into a file on the user's computer in real time. Vital parameters such as examination remaining time, candidates already chosen answers, questions already attempted before logging out. This helps to know if the candidate:

- Was having an ongoing examination,

- Has already completed the exam, or

- Is about to attempt an examination freshly. 
If the candidate has completed the exam before, he/she will need the admin to enter a retake exam key on his/her behalf. If the candidate is in the process of completing the examination (ongoing exam), he/she will be given the opportunity to continue such.

As can be seen from Figure 12, The Systems GUI is designed with high consideration for ease of use. It is flexible enough to allow examinee attempt different subjects simultaneously e.g. Examinee can switch from mathematics question 3 to physics Question 45. Also, as can be seen from Figure 13, questions with Diagram also have their diagrams displayed during the examination, and for mathematically related subjects, the CBT system is kitted with a basic calculator to assist examinee in performing basic arithmetic calculations. Examinee can log-out at any point in time and return back to continue later using the 'LOG-OUT' button. Exam will auto submit once time is up.

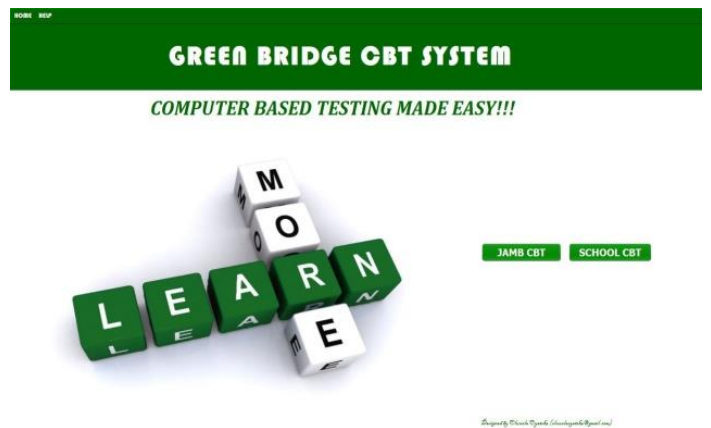

Fig.10. Diagram Showing the CBT Home Screen

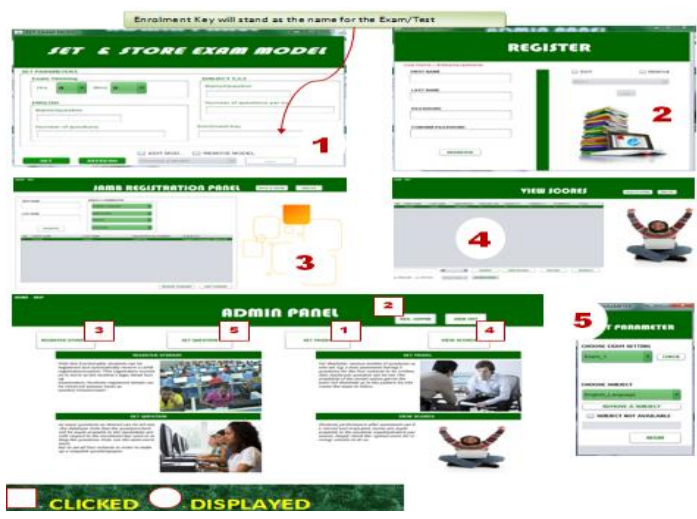

Fig.11. Diagram Showing the JAMB CBT Admin Panel and Its Components

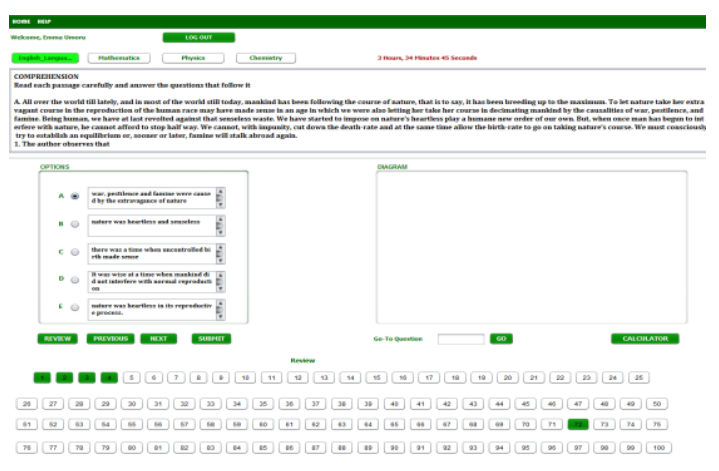

Fig.12. Diagram Showing an Ongoing JAMB Examination

Copyright @ 2015 MECS

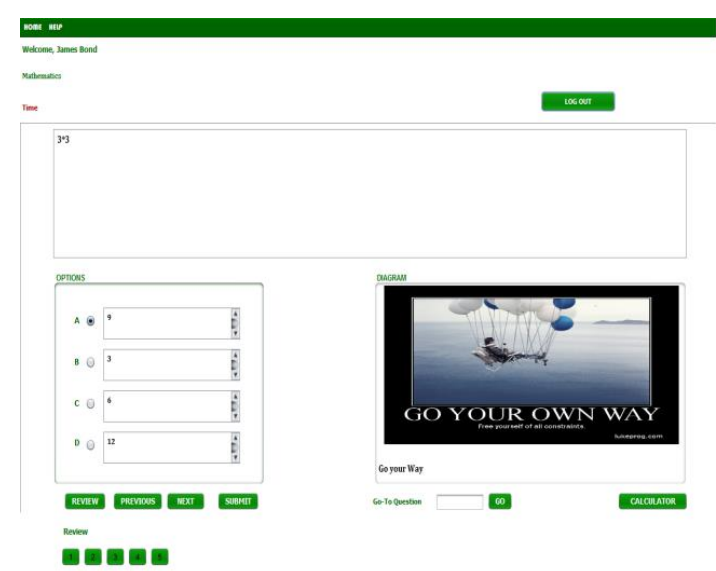

Fig.13. Diagram Showing an Ongoing School CBT

\section{IMPACT ANALYSIS}

In order to understand the impact this software will have on the educational landscape in general, I decided to carry out a survey. This survey naturally is to provide an opportunity to discuss key topics with our target population [11]. Considering the fact that questionnaires should produce valid and reliable demographic variable measures and should yield valid and reliable individual disparities that self-report scales generate [12], the survey was targeted at understanding:

1. The level of value contributed to society by making this software freely available for use which will in turn increase practice time. This will be achieved by measuring improvements in candidates previous test engagement ascribable to their prior exposure to a relevant practice system

2. How readily available practice CBT software were, so as to know how much impact this software will have due to its free for use characteristic.

3. The impact of computer literacy on candidate performance in computer based tests

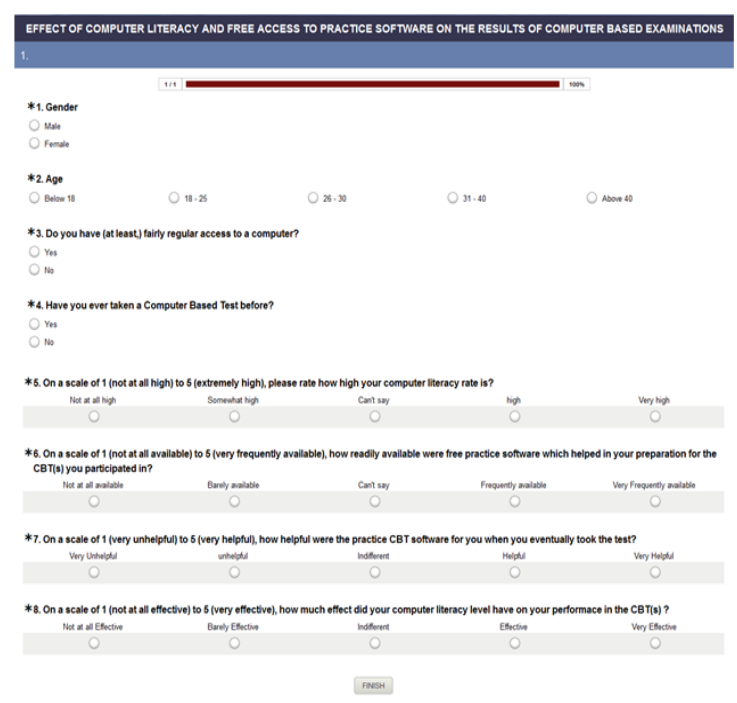

Fig.14. Questionnaire Document 
To achieve this, it was put into consideration the fact that questions in questionnaires need to be concise, brief, specific and grammatically simple while only asking respondents about one issue at a time [13].

The survey was titled 'Effect Of Computer Literacy And Free Access To Practice Software On The Results Of Computer Based Examinations'. Fig. 14 below shows the questionnaire's outlook.

\section{A. Demographics}

The survey had 100 respondents (a mix of both male and female), with $90 \%$ haven engaged in $\mathrm{CBT}(\mathrm{s})$ in the past. $98 \%$ had fairly regular access to a computer. The details of the survey's targeted understanding, the questions associated to each of them and results obtained are as follows.

1) The level of availability of free practice software in previous CBT engagements

Question: On a scale of 1 (not at all available) to 5 (very frequently available), how readily available were free practice software which helped in your preparation for the CBT(s) you participated in.

\section{Result:}
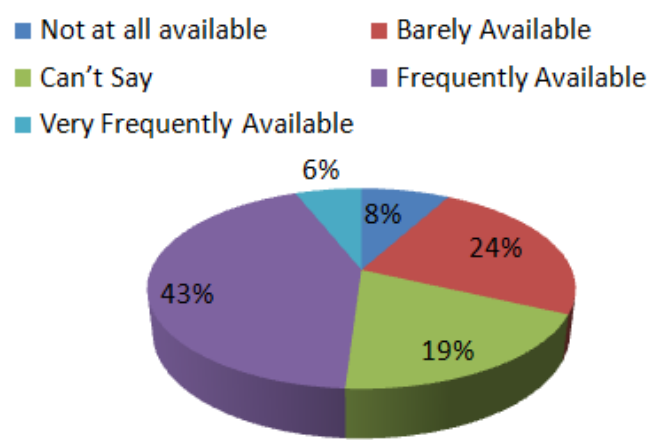

Fig.15. Chart, Showing the Degree of Availability of Free Practice CBT Systems

2) The level of improvement their prior experience and exposure to a practice software brought about.

Question: On a scale of 1(very unhelpful) to (very helpful), how helpful were the practice CBT software for you when you eventually took the test?

\section{Result:}

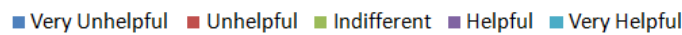

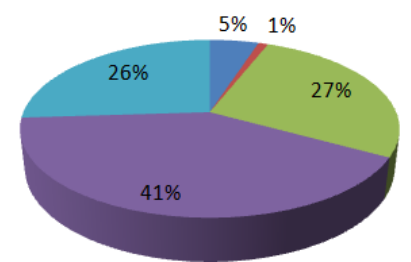

Fig.16. Chart, Showing the Degree of Effectiveness of the Available Free CBT Practice Software

3) The level of effect computer literacy level has on candidates performance in CBTs
Question: On a scale of 1 (not at all effective) to 5 (very effective), how much effect did your computer literacy level have on your performance in the CBT(s)?

Result:

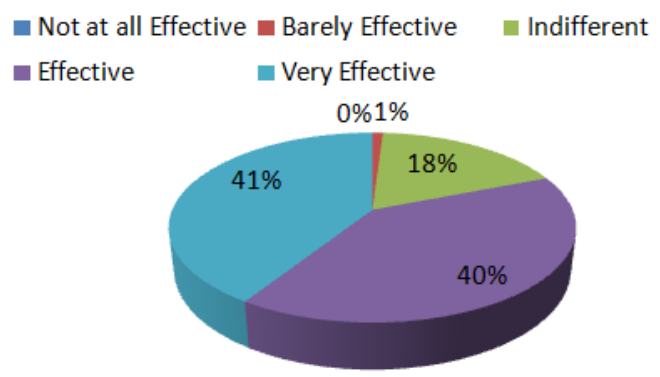

Fig.17. Chart, Showing the Effect of Computer Literacy on Test Performance

Analysis:

The result of the survey indicates that:

1. Free Practice CBT Software are readily available.

2. The Practice CBT Software were found very effective and helpful.

3. Increased Computer Literacy level had positive effects on examinee's performances in tests.

Overall, it can be deduced and concluded that the critical impact that will be made by this software will be in its improvement of examinees test performance due to its availability for continual practice before tests. It also is evident that institutions (majorly high schools) who can provide this technology at next to no cost to its students will record increased CBT scores (as can be deduced from survey that access to practice systems improves performances).

\section{OPEN ACCESS INFORMATION}

To get access to this software, user manual, online use, and download for adaptation purposes, visit https://cbt.oluwoleoyetoke.com. This will offer intending users the opportunity to lay hands on quality products, as it agreed that open source software get closest to what users want because those users can have a hand in making it so. One recent research has shown that in fact, the technical superiority is typically the primary reason enterprises choose open source software [14].

\section{CONCLUSION}

Over the past four decades, there has been incremental growth in computer-based testing (CBT) as a viable alternative to paper-and-pencil testing. However, the transition to CBT is neither easy nor inexpensive [15]. This paper provides a breakdown of the design and implementation process of a Computer Based Testing System followed by a breakdown analysis of the impact of this system on intending users. It can be concluded that 
making this software freely available for use and modification will improve the educational outlook in Africa and on a global scale. This is because many African countries are now fast adopting this method of examination delivery.

\section{ACKNOWLEDGMENT}

I wish to acknowledge the contributions of Emmanuel Umoru and Ireoluwa Obatoki on their efforts in making sure the impact analysis survey was well participated in.

\section{REFERENCES}

[1] Thurlow, M., Lazarus, S. S., Albus, D., \& Hodgson, J. (2010). Computer-based testing: Practices and considerations (Synthesis Report 78). Minneapolis, MN: University of Minnesota, National Center on Educational Outcomes.

[2] Computer - Based Testing (Building the Foundation for future assessment) Edited by Craig N. Mills, Maria T. Potenza, John J. Fremer, William C.W published by Psychology Press 2014

[3] Computer penetration survey, http://www.humanipo.com/news/3079/survey-shows-lessthan-five-percent-of-nigerians-have-access-to-pc/, retrieved $14^{\text {th }}$ April, 2014.

[4] World Top 10 Computer Users, http://www.mapsofworld.com/world-top-ten/world-topten-personal-computers-users-map.html, Retrieved $14^{\text {th }}$ April, 2014.

[5] GUI - Graphical User Interface, http://www.webopedia.com/TERM/G/Graphical_User_Int erface_GUI.html. Retrieved $16^{\text {th }}$ May, 2015.

[6] Graphical User Interface, www.google.com. Retrieved $17^{\text {th }}$ May, 2015.

[7] Tutorials Point, 'MySQL Tutorial', Page 13.

[8] Paul and Harvey Deitel, 'Java How to Programme', 9h Edition, Page 1172, Patience Hall, 2012.

[9] Larman, Craig (June 2003). "Iterative and Incremental Development: A Brief History" (PDF). Computer 36 (6): 47-56. doi:10.1109/MC.2003.1204375. ISSN 0018-9162

[10] Iteritative and incremental development, http://en.wikipedia.org/wiki/Iterative_and_incremental_de velopment. Retrieved $16^{\text {th }}$ May, 2015.

[11] Why Survey?, http://knowledgebase.supersurvey.com/survey-goals.htm. Retrieved $15^{\text {th }}$
May, 2015.

[12] Shaughnessy, J.; Zechmeister, E.; Jeanne, Z. (2011). Research methods in psychology (9th ed.). New York, NY: McGraw Hill. pp. 161-175Iii.

[13] Get The Most Out of Your Survey: Tips for Writing Effective Questions, https://fluidsurveys.com/university/get-the-most-out-ofyour-survey-tips-for-writing-effective-questions/. Retrieved $11^{\text {th }}$ ay, 2015.

[14] 10 Reasons Open Source is good for Business, http://www.pcworld.com/article/209891/10_reasons_open _source_is_good_for_business.html. Retrieved 14th May, 2015.

[15] Richard M. Luecht and Stephen G. Sireci, A Review of Models for Computer-Based Testing, published by The College Board 2011

\section{Authors' Profile}

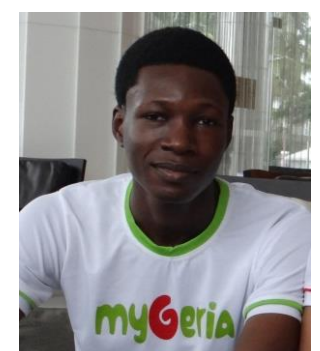

Oluwole Oyetoke is a graduate of Information and Communication Engineering (Year 2014) at the Department of Electrical and Information Engineering, Covenant University, Ota. Nigeria. In research, he has been focusing on the use of application software development in improving the quality of delivery of education across African Universities. Designing and Developing a Simulation package for data communication, aimed at contributing to Simulation Based Engineering Learning in third world universities lacking the financial manpower to purchase vital Communication Engineering hardware. His current interest is focused on Mastering in Embedded Systems Engineering. Oluwole Oyetoke is a member of IEEE (Institute of Electrical and Electronics Engineers) and also a member of NSE (Nigerian Society of Engineers). He has bagged various awards, including a onetime Procter and Gamble Gold Ace Awards - Power of You (Awarded for being one of the most strategic employee in the first quarter of the 2014/2015 Fiscal Year in Nigeria.

How to cite this paper: Oyetoke Oluwole,"Design and Implementation of an Open-Source Computer-Based Testing System with End User Impact Analysis in Africa", IJMECS, vol.7, no.8, pp.17-24, 2015.DOI: 10.5815/ijmecs.2015.08.03 